IRA-International Journal of Education \& Multidisciplinary Studies

ISSN 2455-2526; Vol.08, Issue 01 (July 2017)

Pg. no. 122-129

Institute of Research Advances

http://research-advances.org/index.php/IJEMS

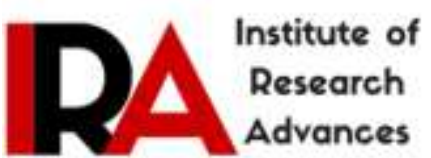

\title{
Impact of Working Conditions on Teacher's Job Satisfaction and Performance in the Private Primary Schools in Yei Town, South Sudan
}

\author{
Alyaha Daniel Felix Ohide \\ Principal, Emmanuel Christian College, Goli - Yei, South Sudan \\ c/o Open Doors, P. O. Box 30870 - 00100, Nairobi, Kenya. \\ Rosemary Wahu Mbogo ${ }^{\#}$ \\ Lecturer, Education Department; and \\ Dean of the School of Education, Arts and Social Sciences (SEAS) \\ Africa International University, P.O. Box 24686 - 00502 Karen, Nairobi, Kenya.
}

Type of Review: Peer Reviewed. " corresponding author.

DOI: http://dx.doi.org/10.21013/jems.v8.n1.p12

\section{How to cite this paper:}

Alyaha, D.O., Mbogo, R.W. (2017). Impact of Working Conditions on Teacher's Job Satisfaction and Performance in the Private Primary Schools in Yei Town, South Sudan. IRA International Journal of Education and Multidisciplinary Studies (ISSN 2455-2526), 8(1), 122-129. doi: http://dx.doi.org/10.21013/jems.v8.n1.p12

(C) Institute of Research Advances.

\section{$(\mathrm{cc}) \mathrm{BY}-\mathrm{NO}$}

This work is licensed under a Creative Commons Attribution-Non Commercial 4.0 International License subject to proper citation to the publication source of the work.

Disclaimer: The scholarly papers as reviewed and published by the Institute of Research Advances (IRA) are the views and opinions of their respective authors and are not the views or opinions of the IRA. The IRA disclaims of any harm or loss caused due to the published content to any party.

Institute of Research Advances is an institutional publisher member of Publishers Inter Linking Association Inc. (PILA-CrossRef), USA. The institute is an institutional signatory to the Budapest Open Access Initiative, Hungary advocating the open access of scientific and scholarly knowledge. The Institute is a registered content provider under Open Access Initiative Protocol for Metadata Harvesting (OAI-PMH).

The journal is indexed \& included in WorldCat Discovery Service (USA), CrossRef Metadata Search (USA), WorldCat (USA), OCLC (USA), Open J-Gate (India), EZB (Germany) Scilit (Switzerland), Airiti (China), Bielefeld Academic Search Engine (BASE) of Bielefeld University, Germany, PKP Index of Simon Fraser University, Canada. 


\begin{abstract}
In South Sudan, teachers have become constant objects of ridicule whenever analysis of examinations is conducted. The poor and deplorable working conditions are among other factors contributing to teachers' levels of job dissatisfaction. This paper examines the impact of working conditions on teacher's job satisfaction and performance in the private primary schools in Yei town, South Sudan. The authors employ a survey design in private schools in Yei town, South Sudan to establish how working conditions affect job satisfaction of teachers and performance in private primary schools. Simple random sampling technique was used to select the respondents from ten private schools. The respondents therefore included 10 head teachers, 100 teachers giving a total of 110 respondents. Questionnaires were used for data collection. Data collected was analysed by the use of Statistical Package for Social Science (SPSS) version 12.0 was and presented in frequencies and percentages and a regression analysis performed to establish the relationships among the variables. The study concluded that the inadequacy of school facilities led to teachers' dissatisfaction with their job.
\end{abstract}

Key words: Environment, Work conditions, Job satisfaction, Teachers, Private primary schools.

\title{
Introduction
}

There has been increased number of transfer requests to the county director of education and teachers quitting the teaching profession. This could be an indicator that teachers in Yei are not satisfied with the situation of affairs. The Division of Yei Town as compared to other Divisions within the larger Yei County showed poor performance in the 2015/2016 national examinations. The poor performance in essence could be attributed to poor working conditions; a situation that prompted the authors to carry out a study to establish the impact of working conditions on job satisfaction among the teachers in private primary schools in Yei Town, South Sudan.

Workers are satisfied when the work place is orderly with adequate tools, materials and a favourable environment while poor equipment and facilities may lead to tension and stress among employees [1]. If working conditions are not conducive, hardworking employees who can find jobs elsewhere leave while mediocre employees would stay [1] When discussing the relationship between employees' working conditions, social conditions and productivity; Shann pointed out thatit was established that performance of workers is influenced by the surrounding and by the coworkers [2]. Teachers value physical surroundings that are safe, comfortable, close to home, areclean, have adequate tools, equipment and buildings that are in good conditions. Halpert adds thatemployees also prefer pleasant working conditions due to their desire for physical comfort and the desire for conditions that facilitate work goals attainment [3].

Herzberg, Mausner and Snyderma[4] list five factors that are said to influence workers' job dissatisfaction and these are: working conditions, company policy and administration, supervision-techniques, salary and interpersonal relations-supervision. According to them those factors are referred to as dissatisfies [4].

According to Bishay[5], teachers were uniformly dissatisfied with poor working tools. This implies that lack of adequate and good working tools and facilities make them dissatisfied with their job. Additionally, previous research conducted in Cyprus by Zembylas revealed that the teachers' job dissatisfaction was associated with poor working conditions: teachers were dissatisfied with inadequate tools and facilities [6]. However, Dinham and Scott [7] conducted research in the United Kingdom and Australia and they associate teachers' job dissatisfaction with extrinsic factors.

Parasuraman[8] conducted a study to identify the work dimension factors that affect job satisfaction of teachers and to ascertain how these factors relate to the aforementioned teachers' characteristics in Tawau, Sabah, Malaysia. A survey was conducted with the participation of 200 teachers. The teachers' job satisfaction was determined by two separate measures namely overall and facet specific job satisfaction. The work dimension factors were clustered into six comprising pay, working conditions, co-workers, promotion, work itself and supervision. This study revealed that secondary school teachers in Tawau, Sabah were generally satisfied with their job.

Additionally, a recent survey of 2,000 educators from California found that 28 percent of teachers who left before retirement indicated that they would go back to employment based on improved working conditions. Monetary incentives were found to be less effective in luring them back [9]. Similarly, Hanushek and Rivkin recently 
concluded that salary affects teacher mobility patterns less than do working conditions, such as facilities, safety, and quality of leadership [1]. A 2008 study of teacher retention found that teachers left their schools primarily because of management breakdowns, challenging relationships (administrators and colleagues as well as students and parents), and the loss of creativity and control in their classrooms [10].

But what counts for working conditions? One recent study revealed how high-stakes accountability negatively influenced teachers by forcing their teaching to become "less deliberate, less individualized, and more homogenized" and pushed decision-making power "further from the classroom and the school [3]." Some analysts have claimed that addressing these working conditions and building a sense of trust in schools are critical factors in reforming schools, as both have been linked to greater teacher effectiveness. One of the most extensive examinations of working conditions data revealed the need to improve teaching as a career [3].

Rosenholtz's[11] landmark study of two decades ago concluded that when teachers work in an environment of collaboration, learning in enhanced with increased individual contribution. Recent studies of highly-accomplished teachers and their career preferences indicate that working conditions matter more than salary when it comes to deciding where they will teach. Others researchers like Berryclaim that growing student diversity can drive teachers away from or toward urban schools [12].

However, there are studies that have recorded different results on factors affecting teacher's job satisfaction and performance. In Kenya, Pamela Adhiambo conducted research to examine factors influencing teachers' level of job satisfaction in public primary schools in Kayole Division, Nairobi County [13]. The objectives of the study were to determine the extent to which remuneration, working conditions, teachers' level of education and work load influence the teachers' level of job satisfaction in Kayole Division, Nairobi County. From the findings of this study, it was noted that 32 percent of the teachers were not satisfied with their job due to heavy work load in terms of number of lessons taught per week. On the other hand, 59 out of the 196 respondents were not satisfied with the conditions of the classrooms.

Yet, Mading had carried out a study to find out the root causes of teacher attrition (teacher dropout) in the conflict affected South Sudan, Central Equatoria State [14]. A case study was conducted in two secondary schools and the national Ministry of Education Science and Technology, in Juba County, Central Equatoria State. Data were collected qualitatively using unstructured interviews and analysis of related documents. The authors opine that perhaps, the movement of teachers out of the teaching profession could be attributed to the fact that, working environments in schools are no longer friendly to teachers: salaries are low, training opportunities are rare and teaching is being viewed as a profession of low income and prestige. The study concluded that teacher attrition and retention are influenced by the interplay of practices, processes and factors that mediate a teacher's decision towards teaching as a profession. This study was guided by equity theory as proposed by Porter and Lawler.

\section{Equity Theory}

Equity Theory was proposed by Porter and Lawler [15]. This theory suggests that employees in any organisation have a tendency of making comparisons of what they get from their respective jobs. The comparisons they make are based on the input-output ratio that is whether there is any relationship between the input and the outcome. In other words, employees compare their income with that of other workers within their organisations or with that of their colleagues in other fields.

According to Porter and Lawler, the perceived equitable rewards are a major input into employee satisfaction. Workers expect to see justice and fairness in terms of the work they do and the fruits of their work. In short, the theory claims that workers assess whether there is fairness in what they get doing the job. This implies that if the employees are fairly rewarded, they become happy or contented with their job and the opposite is true.

\section{Materials and Methods}

The study was carried out among private schools in Yei town, South Sudan. According to A survey design was employed for the study in which quantitative data was collected. The target population for the study involved 10 private primary schools out of which 10 head teachers and 100 teachers were selected. 
The teachers were selected through simple random sampling ensuring unbiasedness, while from each school, one Principal was considered. Kasomo[16] recommends that researchers use the largest possible sample size because statistics calculated from a large sample are more accurate. In order to provide equal participation chance for every member in the school to be included, simple random sampling was used. The total sample size included 10 head teachers and a random sample of 100 teachers from each of the 10 schools giving a total of 110 respondents.

A Self-administered, closed ended questionnaire was used for the study because it had the ability to limit inconsistency and save time as suggested by $A \min [170$. Questionnaires were the most preferred method of data collection in this study because they produce normative data important for analysis. Collected data was analysed and presented in frequencies and percentages.

\section{Results}

The teachers were asked to indicate the extent to which they agreed with the following statements regarding the working condition in their schools.

Table 1. Distribution of how working conditions influence teacher's job satisfaction and performance

\begin{tabular}{llllllllllll}
\hline $\begin{array}{l}\text { Statement on working } \\
\text { condition/school } \\
\text { environment }\end{array}$ & SA & & A & & N & & D & & SD & \\
$\begin{array}{l}\text { Am given adequate freedom to } \\
\text { do my job effectively }\end{array}$ & $\mathbf{F}$ & $\mathbf{( \% )}$ & $\mathbf{F}$ & $\mathbf{( \% )}$ & $\mathbf{F}$ & $\mathbf{( \% )}$ & $\mathbf{F}$ & $(\boldsymbol{\%})$ & $\mathbf{F}$ & $(\boldsymbol{\%})$ \\
$\begin{array}{l}\text { I am provided adequate } \\
\text { facilities to do my job }\end{array}$ & 24 & 25.2 & 40 & 42.1 & 19 & 20.0 & 9 & 9.5 & 4 & 4.2 \\
$\begin{array}{l}\text { I believe that the work } \\
\text { atmosphere is friendly }\end{array}$ & 30 & 31.6 & 36 & 37.9 & 20 & 21.1 & 9 & 9.5 & \\
$\begin{array}{l}\text { I know what is expected of me } \\
\text { at my place of work }\end{array}$ & 46 & 48.4 & 38 & 40.0 & 8 & 8.4 & 3 & 3.2 & & \\
\hline
\end{tabular}

A significant number (42.1\%) agreed with the statement that they are given adequate freedom to do their job effectively in regards to the working conditions in their respective schools. This was further supported by almost a quarter of them (24.2\%) who strongly agreed with the statement. Slightly more than half of the respondents (59\%), either strongly agreed or agreed with the statement that they are provided with adequate facilities to their job. Although, $21.1 \%$ of the respondents disagreed to the statement while $17.9 \%$ of them were neutral or undecided.

In regards to the statement if the teachers believe that their work atmosphere is friendly, majority of the respondents $(69.5 \%)$ either strongly agreed or agreed to the statement. $21.1 \%$ of the were undecided. An overwhelming majority (88.4\%) either strongly agreed or agreed to the statement that they know what it is expected of them in their place work. From related findings, it can be concluded that the working conditions of the most private schools in Yei Town are favorable to teachers.

Furthermore, respondents were further asked to indicate their extent of agreement regarding the various statements in regards to career advancement and promotions. 
Table 2. Distribution of how career advancement and promotion influence teacher's job satisfaction and

\begin{tabular}{|c|c|c|c|c|c|c|c|c|c|c|}
\hline \multirow{3}{*}{$\begin{array}{ll}\begin{array}{l}\text { Elements } \\
\text { advancement }\end{array} & \text { of }\end{array}$} & \multirow{2}{*}{\multicolumn{2}{|c|}{ SA }} & & & & & \multirow{2}{*}{\multicolumn{2}{|c|}{ D }} & \multirow{2}{*}{\multicolumn{2}{|c|}{ SD }} \\
\hline & & & \multicolumn{2}{|l|}{$\overline{\mathbf{A}}$} & \multicolumn{2}{|l|}{$\mathbf{N}$} & & & & \\
\hline & $\mathbf{F}$ & $(\%)$ & $\mathbf{F}$ & $(\%)$ & $\mathbf{F}$ & $(\%)$ & $\mathbf{F}$ & $(\%)$ & $\mathbf{F}$ & $(\%)$ \\
\hline $\begin{array}{l}\text { I am satisfied with my chances } \\
\text { for promotion }\end{array}$ & 27 & 28.4 & 26 & 27.4 & 15 & 15.8 & 12 & 12.6 & 15 & 15.8 \\
\hline $\begin{array}{l}\text { Those who do well on the job } \\
\text { stand a fair chance of being } \\
\text { promoted }\end{array}$ & 38 & 40.0 & 33 & 34.7 & 10 & 10.5 & 4 & 4.2 & 10 & 10.5 \\
\hline $\begin{array}{l}\text { There is very little chance for } \\
\text { promotion on my Job }\end{array}$ & 20 & 21.1 & 25 & 26.3 & 22 & 23.2 & 12 & 12.6 & 15 & 15.8 \\
\hline $\begin{array}{l}\text { I have an opportunity to learn } \\
\text { and grow }\end{array}$ & 47 & 49.5 & 36 & 37.9 & 7 & 7.4 & 3 & 3.2 & 2 & 2.1 \\
\hline
\end{tabular}

Slightly more than a half of the teachers $(55.8 \%)$ either strongly agreed or agreed there are satisfied with their chances of promotions. However, $15.8 \%$ were undecided while the rest of them either strongly disagreed or disagreed.

When asked if those who do well on the job stand a fair chance of being promoted, considerable number of the teachers $(40 \%)$ strongly agreed to that statement. Moreover, this was further supported by almost a quarter of them $(34.7 \%)$ who strongly agreed with the statement. Only $5.3 \%$ of them either strongly disagreed or disagreed to the latter.

A significant number of the respondents (47.4\%) either strongly agreed or agreed with the statement that there is very little chance for promotion in their respective jobs. However, $23.2 \%$ of them were undecided. An overwhelming majority of the teachers $(87.4 \%)$ either strongly agreed or agreed to the statement that they have an opportunity to learn and grow.

To have a deeper understanding teacher's job satisfaction and performance in school, the teachers were asked to indicate their extent of agreement regarding the various statements on the relation with peers.

Table 3. Distribution of how peer's relation influence teacher's job satisfaction and performance

\begin{tabular}{llllllllllll}
\hline Peer relation items & SA & & A & & N & & D & & SD \\
& F & $(\boldsymbol{\%})$ & F & $(\boldsymbol{\%})$ & $\mathbf{F}$ & $(\boldsymbol{\%})$ & $\mathbf{F}$ & $(\boldsymbol{\%})$ & $\mathbf{F}$ & $(\boldsymbol{\%})$ \\
I have best friends at work & 56 & 58.9 & 26 & 27.4 & 7 & 7.4 & 3 & 3.2 & 3 & 3.2 \\
$\begin{array}{l}\text { My colleagues are cooperative } \\
\text { in term of teamwork }\end{array}$ & 55 & 57.9 & 22 & 23.2 & 14 & 14.7 & 4 & 4.2 & & \\
$\begin{array}{l}\text { My friends give advice and } \\
\text { feedback towards my } \\
\text { performance }\end{array}$ & 36 & 37.9 & 38 & 40.0 & 13 & 13.7 & 6 & 6.3 & 2 & 2.1 \\
\hline
\end{tabular}

Majority of the respondents (58\%) strongly agreed to the statement that they have a best friend's at work when asked the extent of their relation with peers. This was further supported by $27.4 \%$ of them agreed with the statement.

In response to the statement if their colleagues are cooperative in term of teamwork, majority of the teachers $(57.9 \%)$ strongly agreed to that statement. This was further supported by $23.2 \%$ of them agreed with the statement. 
An overwhelming majority of the respondents (87.3\%) either strongly agreed or agreed to the statement that their friends give advice and feedback towards their performance. However, $13.7 \%$ of them were undecided on the statement. Overall, it is evident from the research findings that most teachers in this study relate well with their peers.

The teachers were further asked to point out their extent of agreement on statements related to their nature of work. The findings are as shown in table 4 .

Table 4. Distribution of how nature of work influences teacher's job satisfaction and performance

\begin{tabular}{|c|c|c|c|c|c|c|c|c|c|c|}
\hline \multirow[t]{2}{*}{ Nature of Work } & \multicolumn{2}{|l|}{$\mathbf{S A}$} & \multicolumn{2}{|l|}{$\mathbf{A}$} & \multicolumn{2}{|l|}{$\mathbf{N}$} & \multicolumn{2}{|l|}{$\bar{D}$} & \multicolumn{2}{|c|}{ SD } \\
\hline & $\mathbf{F}$ & $(\%)$ & $\mathbf{F}$ & $(\%)$ & $\mathbf{F}$ & $(\%)$ & $\mathbf{F}$ & $(\%)$ & $\mathbf{F}$ & $(\%)$ \\
\hline $\begin{array}{l}\text { The job requires high skills } \\
\text { and knowledge }\end{array}$ & 60 & 63.2 & 26 & 27.4 & 7 & 7.4 & & & 2 & 2.1 \\
\hline $\begin{array}{l}\text { The job is not repetitive and } \\
\text { dull }\end{array}$ & 28 & 29.5 & 40 & 42.1 & 13 & 13.7 & 11 & 11.6 & 3 & 3.2 \\
\hline $\begin{array}{l}\text { The job gives an opportunity } \\
\text { for career enhancement or } \\
\text { advancement }\end{array}$ & 49 & 51.6 & 30 & 31.6 & 10 & 10.5 & 2 & 2.1 & 4 & 4.2 \\
\hline $\begin{array}{l}\text { The job achieves my short and } \\
\text { long term goals }\end{array}$ & 32 & 33.7 & 41 & 43.2 & 8 & 8.4 & 9 & 9.5 & 5 & 5.3 \\
\hline $\begin{array}{l}\text { The job is interesting and } \\
\text { challenging }\end{array}$ & 53 & 55.8 & 30 & 31.6 & 7 & 7.4 & 3 & 3.2 & 2 & 2.1 \\
\hline $\begin{array}{l}\text { The job increases my } \\
\text { responsibility and commitment }\end{array}$ & 51 & 53.7 & 34 & 35.8 & 6 & 6.3 & 2 & 2.1 & 2 & 2.1 \\
\hline $\begin{array}{l}\text { The job is achievable and } \\
\text { attainable }\end{array}$ & 28 & 29.5 & 40 & 42.1 & 17 & 17.9 & 7 & 7.4 & 3 & 3.2 \\
\hline
\end{tabular}

Majority of the teachers (63.2\%) strongly agreed to the statement that the teaching job requires high skills and knowledge. This was further supported by $27.4 \%$ of them who agreed with the statement.

In regards to the statement if whether the job is not repetitive and dull, a good number of the respondents (42.1\%) agreed to the statement. This was further supported by $29.5 \%$ of them who strongly agreed with the statement.

Majority of the respondents (83.2\%) either strongly agreed or agreed to the statement that the teaching job gives an opportunity for career enhancement or advancement. On the contrary, $10.5 \%$ of them were undecided while $6.3 \%$ either strongly disagreed or disagreed with the statement.

In regards to the statement, 'the job achieves my short and long term goals', a considerable figure of the respondents $(43.2 \%)$ agreed to that statement. Furthermore, this was supported by $33.7 \%$ of them who strongly agreed with the statement.

An overwhelming majority of the respondents (87.2\%) either strongly agreed or agreed to the statement that their job is interesting and challenging.

An overwhelming majority of the respondents (89.5\%) either strongly agreed or agreed to the statement that the teaching job increases their responsibility and commitment. Only $4.2 \%$ of them either strongly disagreed or disagreed and comparable percentage $(6.3 \%)$ was undecided. 
A substantial number of the teachers $(42.1 \%)$ agreed to the statement that the teaching job is achievable and attainable. Furthermore, this was supported by $29.5 \%$ of them who strongly agreed with the statement.

Having an idea of extent of agreement on statements related to teacher's nature of work in regards to how it influence teacher's job satisfaction and performance, the authors intended to find out further the extent of agreement on statements related to the organization culture and its impact on teacher's job satisfaction and performance.

Table 5: Distribution of how organisation culture influence teacher's job satisfaction and performance

\begin{tabular}{|c|c|c|c|c|c|c|c|c|c|c|}
\hline \multirow[t]{2}{*}{ Organisational Culture } & \multicolumn{2}{|l|}{$\mathbf{S A}$} & \multicolumn{2}{|l|}{$\mathbf{A}$} & \multicolumn{2}{|l|}{$\mathbf{N}$} & \multicolumn{2}{|l|}{$\mathbf{D}$} & \multicolumn{2}{|l|}{ SD } \\
\hline & $\mathbf{F}$ & $(\%)$ & $\mathbf{F}$ & $(\%)$ & $\mathbf{F}$ & $(\%)$ & $\mathbf{F}$ & $(\%)$ & $\mathbf{F}$ & $(\%)$ \\
\hline Open flow of information & 23 & 24.2 & 29 & 30.5 & 23 & 24.2 & 11 & 11.6 & 9 & 9.5 \\
\hline $\begin{array}{l}\text { Provides degree of flexibility } \\
\text { and freedom to make } \\
\text { decisions }\end{array}$ & 23 & 24.2 & 31 & 32.6 & 16 & 16.9 & 16 & 16.9 & 9 & 9.5 \\
\hline $\begin{array}{l}\text { Participate in making } \\
\text { organisational changes }\end{array}$ & 21 & 22.1 & 35 & 36.8 & 22 & 23.2 & 10 & 10.5 & 7 & 7.4 \\
\hline $\begin{array}{l}\text { Provided with adequate } \\
\text { information for decision } \\
\text { making }\end{array}$ & 26 & 27.4 & 31 & 32.6 & 17 & 17.9 & 11 & 11.6 & 10 & 10.5 \\
\hline
\end{tabular}

Slightly more than a half of the respondents (54.6\%) either strongly agreed or agreed with the statement that there is open flow of information in their organisation culture. However, $24.2 \%$ of them were undecided.

Majority of the teachers (56.8\%)either strongly agreed or agreed with the statement that their respective schools provide a degree of flexibility and freedom to make decisions This was however not the case among a number of them $(26.8 \%)$ who either strongly disagreed or disagreed to the statement.

A considerable number of respondents (36.8\%) agreed with the statement that they participate in making organisational changes in their respective schools. This was further supported by $22.1 \%$ of them who strongly agreed with the statement.

Majority of the teachers $(60 \%)$ either strongly agreed or agreed with the statement that they are provided with adequate information for decision making in their respective organisation. On the hand, a number of them (22.1\%) either strongly disagreed or disagreed with the statement.

In terms of various factors affecting teacher's job satisfaction and performance in relation to working environment, it may be concluded that there are indeed quite a number of environment related factors that include; career advancements, organisational culture, peer relations and nature of work among others. All these have been seen to influence teachers' job satisfaction in private schools in Yei Town both positively and negatively.

\section{Conclusion}

Concerning working conditions, the study concluded that the inadequacy of school facilities led to teachers' dissatisfaction with their job. Working atmosphere also affected teachers' level of satisfaction with some teachers citing very dissatisfied. However, from the study findings, other elements of the school environment have been cited. 


\section{Recommendations}

National and local governments should provide adequate instructional materials for teachers' use in order to enhance teacher job satisfaction, as well as students' learning.

It will also be important to work individually with school and County leaders to investigate the needs of the teachers that could enhance teaching and learning processes.

Principals should make an effort to improve their relationships with teachers cordially to promote teacher job satisfaction. Thus, each school in each county is unique and should be treated as such. School leadership should consistently seek to establish what the needs of their teachers and provide solutions to address those needs.

\section{References}

[1] Hanushek, E. \& Rivkin, S. (2003). Pay, working conditions, and teacher quality. The Future of Children, 17(1), 69-86.

[2] Shann, M. (2001). Professional commitment and satisfaction among teachers in urban middle schools. The Journal of Educational Research, 92 (2), 67-073.

[3] Halpert, M. (2011). Factors that influence the satisfaction levels of teachers in urban school districts. Doctoral Dissertation, Arizona State University.

[4] Herzberg, W., Mausner, B., \& Snyderman, B. (1959). Motivation to work. New York: John Wiley\& Sons.

[5] Bishay, A. (2006). Teacher motivation and job satisfaction: A study employing the experience sampling method. Journal of Undergraduate Sciences, Vol.3, 147-154

[6] Zembylas, P. (2006). Sources of job satisfaction and dissatisfaction in Cyprus. British Association for International and Comparative Education, 36(2), 229-247.

[7] Dinham, S. \& Scott, C. (2000). Moving into the third outer domain of teacher satisfaction. Journal Educational administration, 38(4), 379- 396.

[8] Parasuraman, B. (2009). The work dimension factors that affect the job satisfaction of the teachers and to ascertain how these factors relate to the aforementioned teachers' characteristics. Malaysia: Tawau, Sabah.

[9] Futernick, K. (2007). A possible dream: Retaining California teachers so all students learn. Sacramento: California State University.

[10] Ingersoll, R. (2003). Who controls teachers' work? Power and accountability in America's schools. Cambridge, MA: Harvard University Press.

[11] Rosenholtz, S. (2009). Teacher's workplace: The social organization of schools. New York: Longman.

[12] Berry, B. (2007). Recruiting and retaining quality teachers for high-needs schools: Insights from NBCT summits and other policy initiatives. Washington, DC: National Education Association

[13] Adhiambo, P. (2012). Examining factors influencing teachers' level of job satisfaction in public primary schools in Kayole Division, Nairobi County. Unpublished Thesis, University of Nairobi.

[14] Mading, M. (2015). The root causes of teacher attrition (teacher dropout) in the conflict affected South Sudan, Central Equatorial State: Case Study of Garang Memorial schools.

[15] Lawler, E., \& Porter, J. A Casual correlation test of need hierarchy concept. Organizational Behavior and Human Performance April 1972, pp. 265-287.

[16] Kasomo, D. (2007). Research Methods in Humanities and Education Eldoret: Zapf Chancery.

[17] Amin, M. (2004). Foundations of statistical inference for social science research. Makerere University, Kampala Uganda. 